\title{
CONHEÇA UM POUCO DE SUA OPÇÃO: ENFERMAGEM *
}

Edna Apparecida Moura Arcuri**

Pode-se dizer que o atual sistema educacional que diz respeito ao ingresso ao curso superior, assim como o número maior de profissões em oferta, são causas de situações conflitantes para muitos jovens, no momento em que precisam fazer uma opção profissional.

Por essa razão, e como vem acontecendo nos anos anteriores, é possível que alguns de vocês tenham optado em dúvida, outros já tenham tentado conquistas anteriores dentro da área biológica e ainda outros não tenham tido confiança em sua capacidade de ingressar no curso de sua real opção, devido o maior número de pontos a ser alcançado.

Disputaram 8.028 vagas na Universidade de São Paulo, em 1982, 132.258 alunos! Parabéns pelo sucesso obtido.

O conhecimento da situação relatada significa para nós, educadores da Escola de Enfermagem da Universidade de São Paulo (EEUSP), a conscientização necessária ao melhor desempenho de nossa função. Se a essência da educação é o amor, como diz Pestalozzi, acreditamos que esse amor não possa vir desvinculado de um compromisso de ajuda, em todas as fases dessa digna tarefa de educar, de conduzir.

Por julgar que a maioria de vocês pouco ou nada conhece sobre a enfermagem, escolhemos para esta ocasião o tema "Conheça um pouco de sua opção: Enfermagem", objetivando transmitir-lhes algumas informações sobre a profissão com que agora começam a tomar contato.

A sensibilidade ao sofrimento e o desejo de confortar pessoas tem sido encontrado nos seres humanos desde os primórdios da humanidade. Notas sobre as civilizações iniciais, Egipcias, Indianas, Chinesas, Astecas e Gregas fazem referências a práticas de cauterizações, sangrias, aplicações, cataplasmas e bandagens; estas civilizações dispunham de pessoas cuja atividade principal era cuidar dos enfermos.

Com o advento do Cristianismo e seus ensinamentos de amor e fraternidade, a cura e o cuidado do doente ganharam novo ímpeto e surgiram pessoas que se dedicavam especialmente ao cuidado do enfermo (do latim infirmus, que significa não firme, portanto o que está debili-

\footnotetext{
* Aula inaugural proferida na Escola de Enfermagem da USP em 4 de março de 1982.

** Professor Assistente do Departamento de Enfermagem Médico-Cirúrgica da Escola de Enfermagem da USP - disciplina Fundamentos de Enfermagem. Mestre en Enfermagem. Enfermeira.
} 
tado). Foram formulados códigos de ética para aqueles que cuidavam dos enfermos, como o juramento de Hipócrates que persiste até hoje.

Entre as pessoas que se converteram ao Cristianismo encontrava-se as matronas romanas; uma delas, Fabiola, transformou sua própria casa em hospital. Durante muitos séculos, entretanto, a atenção organizada aos doentes foi pouco difundida.

Mais tarde, com a finalidade de dar apoio às cruzadas, foram fundadas ordens militares e ordens hospitalares, que tinham como objetivo específico cuidar dos feridos de guerra; essas ordens eram muitas vezes formadas por mulheres e o trabalho militar associava-se à caridade. As ordens monásticas e dos cavaleiros, estabelecidas em várias formas, incluindo entre elas os trabalhadores de saúde, deram início à organização hierárquica.

Os avanços científicos no campo da saúde foram acelerados no século XVI, com as descobertas na área de anatomia e medicina em geral. Paralelamente a esses avanços científicos, ocorreram conquistas na ação social e religiosa através dos anos. O trabalho de São Vicente de Paulo exemplifica este tipo de ação. Ele recomendou profundas modificações nos hospitais após estudar suas condições e fundou, com Louise de Marillac, a ordem "Filhas da Caridade", acreditando que as "irmãs" deveriam receber educação geral e ser treinadas para o trabalho com o doente. São Vicente de Paulo, que também organizou o início do trabalho comunitário na França, provocou reformas no campo da saúde e enfatizou a responsabilidade dos cidadãos com a saúde e o bem-estar das pessoas.

O movimento que teve como conseqüência profundas modificações no campo da Enfermagem, foi conduzido por Florence Nightingale, mulher de grande poder moral e intelectual. Filha de uma rica familia inglesa, ela teve oportunidade de manter contatos com líderes do humanitarismo e, além de falar alemão, francês e italiano como se fosse a sua própria língua, o inglês, a sua educação básica incluiu treino em ciências, matemática e economia política.

A primeira escola técnica de enfermagem havia sido fundada em 1833, na cidade de Kaiserswerth, Alemanha, pelo Pastor Fliedner. Florence visitou essa escola em 1850, quando ficou impressionada com a profunda sabedoria e o conhecimento que o pastor possuia sobre a natureza humana e também com o sistema educacional utilizado em Kaiserswerth. Ao voltar para a Inglaterra ela desejou implantar o mesmo sistema educacional em Londres mas antes que isso acontecesse foi convidada, em 1854, para dirigir os serviços de enfermagem no hospital montado com a finalidade de dar assistência aos feridos da guerra da Criméia, ocorrida entre 1853 e 1856, tendo aceito o convite.

A ausência de roupas, as dificuldades nos serviços de lavanderia, a falta de suprimentos, a alimentação pobre e sobretudo a falta de higiene e de enfermagem eram responsáveis por um índice de mortalidade de $50 \%$ dos soldados ingleses. Lutando arduamente pelo respeito aos prin- 
cípios de higiene e nutrição, ajudada por um grupo de auxiliares, Florence conseguiu baixar os índices para 2,2\%. Ela dedicava-se aos enfermos durante o dia e muitas vezes durante a noite, quando utilizava uma lanterna para iluminar o seu caminho, razão pela qual ficou conhecida como "Dama da Lâmpada".

O conceito de Florence sobre saúde era amplo, demonstrando profunda visão dos problemas a ela relacionados, como pode ser constatado no seguinte texto publicado recentemente pela revista Saúde do Mundo: "Cresce a convicção de que, em todos os hospitais, por melhor que seja a sua administração, perdem-se vidas que poderiam ser poupadas e que, o pobre que recebesse boa assistência médica e de enfermagem, recuperar-se-ia melhor na choça em que vive do que no mais refinado ambiente hospitalar".

Observem, caros alunos, que o texto apresentado sugere grande preocupação pelo problema enfocado atualmente como "Infecções Hospitalares".

Florence Nightingale acreditava na enfermagem como uma carreira independente para mulheres capazes e treinadas. Sugeriu que o serviço de enfermagem fosse administrado por enfermeiras com preparo especial e que o relacionamento entre enfermeiras e médicos fosse profissional. Acreditava também que havia um corpo substancial de conhecimentos e habilidades a serem aprendidos em enfermagem e que as enfermeiras deveriam ser preparadas para cuidar dos doentes em hospitais ou domicílios e ensinar boas práticas de saúde aos pacientes e seus familiares. Florence, a "Precursora da Enfermagem" ou "Dama da Lâmpada", conforme muitos à ela se referem, escreveu incansavelmente e seus pensamentos podem ser conhecidos em algumas publicações, suas cartas e notas, infelizmente não traduzidas para o português até o presente momento. Com relação à função da enfermagem ela escreveu: "Eu uso a palavra enfermagem para desejar algo melhor. Ela tem sido limitada a significar um pouco mais do que a administração de medicamentos e cataplasmas. Ela deveria significar o uso correto do ar fresco, luz, calor, limpeza, silêncio e da seleção e administração adequada da dieta ... tudo com o menor desgaste do potencial de vida do paciente".

Por seu trabalho, na Guerra da Criméia, Florence foi considerada heroina nacional. Recebeu um fundo levantado por uma campanha popular no valor de $£ 44.000$, utilizando-o para fundar a Escola de Enfermagem do Hospital St. Thomas, em Londres, em 1860. O sistema educacional implantado ficou conhecido como Sistema Nightingale, adotado nos Estados Unidos em 1873 e depois em outros países do mundo, entre os quais o nosso.

No Brasil, sabe-se que os primeiros hospitais foram as Santas Casas de Misericórdia, organizadas nos moldes das Santas Casas portuguesas, onde se destacava a atuação das congregações religiosas. As chamadas "Irmãs de Caridade", da ordem criada por São Vicente de Paulo, eram responsáveis pela higiene, conforto e bem-estar dos doentes. 
A Santa Casa de Santos foi fundada em 1543, por Brás Cubas, e nela predominava o compromisso cristão referido no documento de criação das misericórdias de Lisbôa.

Referências especiais com relação a pessoas que cuidaram de doentes (os primeiros "enfermeiros"), são feitas ao Padre Anchieta, no século XVI e ao Frei Fabiano, no século XVIII, que cuidou de enfermos durante quarenta anos, no Convento de Santo António do Rio de Janeiro.

Em 1814 nasceu, no Estado da Bahia, Ana Justina Ferreira Neri. Casada com um Capitão de Fragata, Ana Neri teve três filhos que foram lutar na Guerra do Paraguai. Com 51 anos de idade, a ilustre mãe de família solicitou ao exército permissão para acompanhar seus filhos e parentes à guerra. Nos campos de batalha cuidou dos feridos brasileiros e paraguaios com grande dedicação e mais tarde passou a ser chamada "A Mães dos Brasileiros". Voltando ao Brasil foram-lhe conferidas honrarias e seu retrato figura no pátio da cidade de Salvador.

No Brasil, a primeira escola de enfermagem da qual se tem conhecimento é a "Escola Profissional de Enfermeiros e Enfermeiras", criada no Rio de Janeiro, em 1890, cuja preocupação maior era o cuidado dos doentes mentais. Em 1942 esta escola passou a ser chamada "Alfredo Pinto" e só em 1949 passou a cumprir com os dispositivos legais referentes ao ensino da enfermagem.

Somente no início do atual século a enfermagem começou a ter maior desenvolvimento no Brasil, de início com a fundação da Cruz Vermelha, nos moldes da de Genebra, tendo sido Osvaldo Cruz o seu primeiro presidente. No que diz respeito à Saúde Pública, a enfermagem tomou impulso após a campanha sanitária empreendida por Osvaldo Cruz e a subseqüente atuação de seu discípulo Carlos Chagas.

O cientista Carlos Chagas, quando dirigiu o Departamento Nacional de Saúde Pública, com a ajuda da Fundação Rockefeller, iniciou o Serviço regular de Visitadoras e fundou a primeira escola de enfermagem no padrão Nightingale, então denominada Escola de Enfermeiras do Departamento Nacional de Saúde Pública, hoje "Escola de Enfermagem Ana Neri".

O Hospital Samaritano foi o berço da enfermagem profissional em São Paulo, segundo publicação da professora Amália Corrêa de Carvalho *. $O$ fato da sociedade mantenedora ser constituída de pessoas estrangeiras, médicos dos Estados Unidos e Inglaterra, países onde o sistema Nightingale estava plenamente $\epsilon \mathrm{m}$ vigor, deu origem à preocupação dos dirigentes em manter um serviço de enfermagem à altura da instituição. Em 1894 foram contratadas cinco enfermeiras inglesas, mas presume-se que o curso de enfermagem tenha sido iniciado por volta de 1901, pois só em 1904 eram contratadas as primeiras enfermeiras diplomadas no Brasil.

\footnotetext{
- Ex-professora da EEUSP e autora de uma das fontes de dados para esta aula: CARVALHO, A. C. de. Escola de Enfermagem da USP: resumo histórico 1942-1980. Rev. Esc. Enf. USP, São Paulo, 14(supl.):1-271, 1980.
} 
Em 1912 foi criada a Escola de Parteiras de São Paulo, que passou a funcionar na Maternidade São Paulo. Em 1931 foi chamada Escola de Obstetricia e Enfermagem Especializada; em 1944 foi transferida para o Hospital das Clínicas da USP, em 1962 integrada à Universidade de São Paulo, anexa ao Departamento de Obstetrícia e Ginecologia da Faculdade de Medicina da USP e só em 1971 foi integrada à Escola de Enfermagem da USP, portanto à nossa escola. Nessa ocasião o curso era coordenado pela atual chefe do Departamento de Orientação profissional e também secretária da escola, Dra. Dilce Rizzo Jorge.

Desde a década de 20 a Fundação Rockefeller desejava que um maior número de moças paulistas fosse preparado na Escola de Enfermagem Ana Néri. Mais tarde, no final da década de 30, a enfermeira Edith de Magalhães Fräenkel foi para os Estados Unidos preparar-se para, ao voltar, atuar na escola que seria fundada anexa à Faculdade de Medicina da USP. Em 1940 foram enviadas duas bolsistas ao Canadá: $D^{a}$ Maria Rosa Sousa Pinheiro e $D^{a}$ Zilda Carvalho e em 1941 mais duas.

A escola foi oficialmente criada em 31 de outubro de 1942, anexa à Faculdade de Medicina da USP, com o nome de Escola de Enfermagem de São Paulo, procurando-se atender os seguintes requisitos:

- residência adequada, salas de aulas e laboratórios com localização nas proximidades da Faculdade de Medicina, Instituto de Higiene (hoje Faculdade de Higiene e Saúde Pública) e Hospital das Clínicas.

- matrículas limitadas às professoras diplomadas em escolas normais, conforme era exigido às educadoras da época.

- abandono de qualquer curso de enfermagem no Departamento de Saúde ou outras instituições.

- curso de 3 anos, no mínimo, com matrícula limitada às mulheres solteiras ou viúvas, que deveriam residir na escola.

A primeira aula inaugural foi dada em 31 de outubro de 1943. Logo após o início das aulas foi criado o Centro Acadêmico 31 de Outubro, que teve como primeira documentação escrita a ata da $1^{\text {a }}$ reunião ordinária realizada em 13 de março de 1944, quando foi eleita presidente a estudante Amália Corrêa de Carvalho.

Em 1948 a escola recebeu o primeiro aluno do sexo masculino.

$D^{n}$ Edith de Magalhães Fraenkel esteve na direção até 1955, quando foi substituida por $D^{\mathrm{a}}$ Maria Rosa Sousa Pinheiro.

Em 1963 a Escola de Enfermagem foi desanexada da Faculdade de Medicina, passando a constituir uma das unidades da USP. No novo estatuto que entrou em vigor em 1970 a Escola de Enfermagem perdeu na denominação a expressão "de São Paulo", passando a denominar-se "Escola de Enfermagem", geralmente identificada e referida como "Escola de Enfermagem da USP". A Escola de Enfermagem da USP localizada na cidade de Ribeirão Preto costuma ser referida de acordo com a sua denominação "Escola de Enfermagem de Ribeirão Preto". 
De 1954 a 1963 "nossa" escola manteve o curso de Auxiliar de Enfermagem. Em 1959 foram iniciados os cursos de Pós-Graduação, que foram realizados até 1969, quando foram suspensos para dar lugar aos cursos de Mestrado, estes iniciados em 1973. Até 1981 foram formados 182 auxiliares e 1.125 enfermeiros, sendo 260 com habilitação em Enfermagem Obstétrica, 262 em Enfermagem de Saúde Pública e 95 em Enfermagem Médico-Cirúrgica. O antigo curso de Pós-Graduação conferiu 491 certificados, sendo 60 da América Latina e África Portuguêsa e o Mestrado possibilitou a formação de enfermeiros, dos quais 67 já obtiveram o grau de Mestre. O curso de Pós-Graduação em nível de Doutorado só agora está sendo iniciado.

$D^{a}$ Maria Rosa Sousa Pinheiro assumiu a direção da escola como vice-diretora em exercício em 1955, tendo sido nomeada diretora em 1956. Permaneceu neste cargo durante 22 anos, uma exceção na Universidade de São Paulo, pois ocupava um cargo efetivo de diretor, tendo assumido com imensa responsabilidade a sua tarefa, trabalhando pela desanexação da escola da Faculdade de Medicina, estimulando e apoiando o desenvolvimento dos docentes, promovendo assim o desenvolvimento da escola. Após sua aposentadoria foi substituída, em 1978, pelo ilustre professor Carlos da Silva Lacaz, nosso diretor atual.

A vice-diretora da escola é a Prof ${ }^{a}$ Dr $^{a}$ Leda Ulson Mattos, a segunda docente desta escola que conseguiu vencer todas as etapas da carreira universitária, tornando-se professor titular. A primeira docente a receber este título foi a saudosa professora Wanda de Aguiar Horta, que faleceu em 1981, para tristeza de todos nós.

A enfermagem está organizada internacionalmente pelo Conselho Internacional de Enfermeiras (ICN), nascido no final do século passado. Hoje, com 82 anos de existência, o ICN é a maior organização internacional no campo da saúde; a ele estão associadas 93 associações nacionais de enfermagem, que representam aproximadamente 1.000 .000 de enfermeiros. O propósito deste Conselho é prover meios pelos quais as associações nacionais possam compartilhar seus interesses comuns e trabalhar juntas, para desenvolver a contribuição da enfermagem na promoção da saúde das pessoas e no cuidado do doente. Sediado em Genebra, o ICN reune-se cada quatro anos em Congresso Internacional.

A Associação Brasileira de Enfermagem (ABEn), fundada em 1926, filiada ao ICN em 1929, está sediada em Brasília e estruturada em seções estaduais. A presidente da ABEn central é a ilustre enfermeira Dra Circe de Melo Ribeiro e a da seção de São Paulo a Dra Taka Oguisso, ambas docentes do Curso de Pós-Graduação desta escola.

A ABEn é uma entidade cultural que tem por finalidade "pugnar pelo desenvolvimento profissional e pelo aprimoramento científico-cultural de seus membros".

Os órgãos que regulam o exercicio profissional da enfermagem são os Conselhos. O Conselho Federal de Enfermagem (COFEN), sediado 
no Rio de Janeiro, é um órgão normativo, e os Conselhos Regionais de Enfermagem (COREN) nos Estados são órgãos executivos. A presidente do COFEN é a Dr Maria Ivete Ribeiro de Oliveira, da Bahia, doutora em enfermagem por esta escola, e a do COREN-São Paulo a enfermeira Maria Lúcia Pimentel Assis Moura, mestre em enfermagem por esta escola.

Outra entidade de caráter cultural é a Associação Brasileira de Educação em Enfermagem (ABEE), sociedade de caráter técnico-científico-cultural, de âmbito nacional, que tem como finalidade o desenvolvimento da educação em enfermagem, contribuindo assim para a elevação do nivel da saúde e bem-estar da comunidade brasileira.

Além das entidades culturais e da entidade disciplinadora da profissão existem também as entidades de defesa da classe, que são os sindicatos, órgão de finalidade econômica, social, defesa e representação da classe. Em alguns Estados, como o de São Paulo, ainda não existe sindicato; existe a Associação Profissional, que o precede, e cujo funcionamento oferece as bases para a concessão da carta sindical pelo Ministério do Trabalho.

Prezados alunos: muitas horas de estudo, dedicação, ... era o desafio do vestibular! Os gabaritos, a lista dos aprovados ... finalmente o resultado, o ingresso na USP! O abraço dos familiares e amigos.

Passada a euforia dos primeiros dias e o merecido descanso, talvez alguns de vocês tenham questionado: Enfermagem... o que é esta profissão? O que terei a aprender e a fazer?

Virginia Henderson, enfermeira americana, um dos vultos mais expressivos da enfermagem nas últimas décadas, por volta de 1958 atestou: "a função específica do enfermeiro é assistir o indivíduo, doente ou sadio, no desempenho das atividades que contribuem para a sua saúde ou recuperação, ou a morrer em paz, atividades estas que ele poderia desempenhar sem ajuda, se tivesse a necessária força, poder e conhecimento... e fazê-lo de tal forma que o ajude a alcançar a independência tão rápido quanto possível".

Revisando seu conceito de enfermagem em publicação de 1978, 20 anos depois, Henderson afirmou que, "para atender às necessidades das pessoas, os profissionais da equipe de saúde precisam rever seus papéis com bom senso e modificar os programas de ensino que os preparam. Enquanto o papel dos médicos, enfermeiros e outros profissionais estão sendo questionados, como num estado fluido, comenta a autora, algum profissional da equipe de saúde necessita dar assistência às pessoas, em suas atividades diárias essenciais, quando elas não têm conhecimento e força, livrando-as do estado de carência e levando-as em direção a uma independência saudável". Este serviço é, para Henderson, o elemento universal do conceito de enfermagem, serviço que oferece profunda recompensa emocional $\mathrm{e}$ intelectual àquelas que o prestam e alta valorização daqueles que o recebem. 
Muitos exemplos poderiam ser dados nessa função assistencial, começando pelo aconselhamento genético por ocasião da concepção, até o auxílio para morrer em paz e com dignidade.

As necessidades essenciais citadas por Henderson chamadas por Maslow de "necessidades básicas do ser humano" do mesmo modo referidas por Wanda de Aguiar Horta são: a oxigenação pela respiração normal; a hidratação e alimentação adequadas, assim como a eliminação das perdas corporais; a manutenção da temperatura corporal, da postura e movimentação desejada; a possibilidade do sono e repouso; a proteção do tegumento e sua limpeza; a necessidade de segurança; a comunicação correta, que expresse emoções, necessidades, etc.; a certeza de ser amado e livre; a auto estima; a prática de cultos segundo a fé; o trabalho visando realização pessoal; a recreação e, enfim, a satisfação da curiosidade que leva ao desenvolvimento normal da saúde e o uso de facilidades e recursos disponiveis de saúde.

Será que a função assistencial é uma função independente? Evidentemente não. O seu aprimoramento depende de três outras funções específicas: administração, pesquisa e ensino.

Administrar em enfermagem, segundo a professora Paulina Kurcgant *, significa criar infra-estrutura para que as atividades referentes aos cuidados diretos e indiretos aos indivíduos sejam desenvolvidas; é o levantamento dos recursos materiais e humanos dessa infra-estrutura, para o atendimento das necessidades; é a elaboração, execução e avaliação do programa de desenvolvimento do pessoal de enfermagem, ou seja a educação em serviço, a educação continuada das enfermeiras e a orientação da equipe multiprofissional para execução de programas de assistência à saúde do indivíduo, família e comunidade.

Pesquisa: a enfermeira consciente de suas responsabilidades, deve impor para si a determinação dos métodos que usa em sua área de especialidade. A preocupação maior deve recair sobre a assistência de enfermagem. Muitos procedimentos que envolvem o cuidado básico de enfermagem, como o relacionamento com o paciente, o que pode ou não ser feito, o que deve ou não ser dito, são muitas vezes baseados em tradições e ações aprendidas empiricamente, com pouco ou sem qualquer suporte cientifico.

A utilização do método científico, "o que, o porquê, como, quando e onde" dos acontecimentos deve conduzir as açōes do profissional consciente e a pesquisa deve surgir sempre que a dúvida interceptar essas ações.

Com relação à pesquisa em enfermagem tivemos recentemente 0 pronunciamento feliz da professora Circe de Melo Ribeiro, por ocasião de um curso de metodologia científica, quando disse: "a capacidade de pensar corretamente é o objetivo-prêmio que o estudante deve alcançar

- Professor Assistente do Departamento de Orientação Profissional da Escola de Enfermagem da USP - disciplina Administração Aplicada à Enfermagem. Mestre em Enfermagem. 
no curso de graduação e pós-graduação, se a universidade realmente estiver dirigida para a formação de seres pensantes, de pessoas que possam liderar no campo do conhecimento, da ideação e do comportamento..." "a introdução dos universitários à metodologia da ciência os expõem a um horizonte infinito de possibilidades futuras, na medida em que dominem as técnicas especializadas e as teorias aceitas. $O$ pesquisador de enfermagem será aquele que dedicar com perseverança seus esforços à investigação criadora, de forma incessante, investigação que irá descobrir verdades novas, previstas ou não nos protocolos de pesquisa."

Algumas qualidades inerentes ao pesquisador, citadas pela referida professora são: vocação autêntica e profunda, dedicação constante, idealismo, luta por ideais maiores como ciência, pátria, humanidade, iniciativa, espírito de investigação, imaginação criadora, capacidade de sintese, espírito crítico rigoroso porém não destruidor, responsabilidade, potencialidade, perseverança, concentração e honestidade.

Como vêem, a tarefa não é fácil! Entretanto, alunos ingressantes, muitas dessas qualidades não são exigidas apenas para a pesquisa mas também para qualquer função que o enfermeiro assuma. Dai a grande responsabilidade daqueles que exercem a última função que agora abordamos, que é o ensino de enfermagem.

Falando sobre educação no último congresso do ICN, realizado em Los Angeles, em julho de 1981, citamos as profundas reflexões do eminente educador Paulo Freire, o qual chama a atenção sobre a concepção humanistica e libertadora da educação moderna, que tem como propósito o desenvolvimento do homem de dentro para fora e sua formação de fora para dentro, baseada num presente dinâmico em que o futuro é visto como diferente do passado. Citamos também o eminente professor Lobo, o qual afirma que a educação deve permitir o desenvolvimento das potencialidades individuais sem admitir privilégios, aceitando o caráter competitivo da vida e o fato de que os homens são diferentemente dotados.

É grande a responsabilidade daqueles que escolhem a educação como profissão ... Educar não é apenas transmitir conhecimentos! Esses, às vezes, até podem ser adquiridos individualmente, na ausência do mestre através das inúmeras conquistas no campo da tecnologia educacional. O mais difícil é o alcance dos chamados objetivos afetivos, que dizem respeito à formação dos valores profissionais.

Especial atenção deve ser dispensada ao desenvolvimento psicossocial do aluno, no período tão marcante que é o da universidade; nessa fase ele deve encontrar as condições necessárias ao desenvolvimento e consolidação definitiva das características intrínsecas de sua personalidade e de seu caráter.

Sabemos nós, docentes da EEUSP, que a tarefa de educar é difícil. Sabemos que temos que questionar como estão saindo os jovens que nesta casa depositaram sua confiança. Sabemos que estamos comprometidos e conhecemos as nossas limitações. Sim, temos limitações, mas 
estamos lutando para atingir o melhor desempenho porque acreditamos que podemos conseguí-lo. Acreditamos porque sentimo-nos comprometidos na formação de pessoas que possam construir um mundo melhor; acreditamos porque a enfermagem deve conjugar esforços para desenvolvimento, educação, investigação, tecnologia e teoria, se quiser desempenhar com dignidade o seu papel na vida do homem.

Estamos comprometidos porque cada professor deve ser guiado por fé inabalável, esperança e entusiasmo no alcance de suas realizações. Enfim, estamos comprometidos porque devemos aceitar o desafio "Saúde para todos no ano 2000" da Organização Mundial de Saúde, no qual deverão basear-se nossas ações futuras.

Prezados alunos, sejam bem-vindos. Assumam com dignidade desde agora a enfermagem. Ajudem-nos em nossas metas e propósitos.

Se alguns de vocês, entretanto, perceber que a escolha foi inadequada, não vacilem em procurar e recomeçar em outra profissão; se, porém, descobrir depois, que desejam voltar, como tem acontecido com alguns alunos, não vacilem em reconstruir, porque, para ser feliz, o homem deve ter:

"algo para fazer,

algo para amar,

e

algo para acreditar."

\section{B I B L I O G R A F I A}

AULD, M. E \& BIRUN, L. H. The challengo of nursing. Saint Louis, Mosby, 1973, 247p.

AUSTIN, A. L. History of nursing. New York, Putman's, 1957. 480p.

CARVAlHo, A. C. de. Escola de enfermagem da USP: resumo histórico 1942-1980. Rev. Esc. Enf. USP, São Paulo, 14 (supl.): 1-271, 1980.

CORNELIUS, D. International Council of Nurses (ICN): Congress salutes spirit, tradition of nursing. Amer. Nurse, New York. 13(6):4, June 1981.

ENCYCLOPAEDIA BRITANNICA: Macropaedia. Chicago, Helen Hemingway Benton, $1973 / 74$. v. 13. p. 395 .

GRANDE ENCICLOPEIIA DELTA LAROUSSE. Rio de Janeiro, Delta, 1976, v. 6, p. 2414.

FRElRe, P. Ação cultural para a liberdade. Rio de Janeiro, Paz e Terra, 1976.

HENDERSON, V. The concept of nursing. J. Adv. Nurs, Oxford, 13(2):113-30, 1978.

LACAZ, C. da S. Lembrando Ana Néri: Rev. Esc. Ent. USP, São Paulo, 14(2):115-6, 1980.

LOBO, L. C. G. O uso de uma nova tecnologia eaucacional na formação de recursos humanos. In: SEMINARIO DE DIDATICA APLICADA AO ENSINO SUPERIOR. Rio de Janeiro,

17-21, fev. 1975. Rlo de Janeiro, Centro Latino Americano de Tecnologia Educacional para a Saúde, 1975.

MITCHELL, P. Concepts basic to nursing. 2. ed. New York, McGraw-Hill, 1977. 575p.

NIGHTINGALE, F. Notes on nursing. New York, Dover, 1969. 79p.

Apud A saúde é um estilo de vida. Saúde do Mundo, Genebra: 36, fev./mar. 1981.

OGUISsO, T. Entidades de classe na enfermagem. Rev. Esc. Ent., Săo Paulo, 1(10):6-10, jan./fev. 1981.

RIBEIRO, C. de M. Aspectos da pesquisa $\in m$ enfermagem. Rev. Esc. Ent., São Paulo, (1):21-2, jul./ago. 1981 . 